\title{
LOS EXILIADOS ARGENTINOS Y LOS SENTIDOS DEL NÚREMBERG: DE RECURSO PEDAGÓGICO A ESTRATEGIA DE PERSECUCIÓN PENAL DE LOS CRÍMENES DE LA ÚLTIMA DICTADURA MILITAR (1976-1983)
}

\author{
Argentine exiles and the senses of the Núremberg: from pedagogical resource \\ to crime persecution strategy of the last military dictatorship (1976-1983)
}

\author{
Silvina Jensen* \\ https://orcid.org/0000-0002-9166-8852
}

\section{Resumen}

Este artículo hace foco en los sentidos que tuvo para los exiliados argentinos apelar a la figura del Núremberg desde una coyuntura temprana de la lucha antidictatorial hasta el ocaso del "Proceso de Reorganización Nacional”. El trabajo parte de la hipótesis que los sentidos del Núremberg fueron modificándose en los diversos contextos políticos, pasando de ser un recurso comunicativo hasta convertirse en una apelación doctrinal. Este paso permitió a los exiliados tipificar la desaparición forzada como crimen de lesa humanidad y descubrir el "juicio y castigo" como nuevo horizonte de lucha en el espacio público internacional.

$<$ exiliados argentinos $><$ Núremberg $><$ esfera pública internacional $><$ última dictadura militar $>$

\begin{abstract}
This article does focus on the senses for Argentine exiles to appeal to the figure of Nuremberg from an early juncture of the anti-dictatorial struggle until the decline of the National Reorganization Process ("Proceso de Reorganización Nacional".) The work is based on the hypothesis that the senses of Nuremberg were modified in various political contexts, from being a communicative resource to become a doctrinal appeal. This step allowed the exiles to typify disappearance as a crime against humanity and to discover the "trial and punishment" as a new horizon for fighting in the international public space.
\end{abstract}

$<$ Argentine exiles $><$ Nuremberg $><$ international public sphere $><$ last military dictatorship $>$

Recibido: 11/12/2018//Aceptado: 11/02/2019

\footnotetext{
* Profesora Asociada, Departamento de Humanidades, Universidad Nacional del Sur (Bahía Blanca, Buenos Aires). Investigadora Independiente del Consejo Nacional de Investigaciones Científicas y Técnicas (CONICET), Argentina, silvinajensenmail@gmail.com
} 
Jensen. Los exiliados argentinos y los sentidos del Núremberg: de recurso pedagógico a estrategia de persecución...

\section{Introducción}

En el último quinquenio y al calor del impacto del giro global en la historiografía, las investigaciones sobre la última emigración política argentina han comenzado a prestar especial atención a los exiliados como actores de la arena internacional y en concreto a aquellas prácticas, representaciones, lenguajes y estrategias de acción transnacional antidictatorial que le permitieron proyectar más allá de las fronteras de los países de residencia el "problema de los desaparecidos" (Jensen, 2016 y 2018), visibilizando no sólo la magnitud represiva que encerraba la dictadura, sino la perversidad de un Estado terrorista que planificó y sistematizó una política de exterminio cimentada en la clandestinidad, el secreto y la negación de responsabilidad en el crimen (Cristiá, 2017; Gordillo, 2017; Catoggio, 2018; Ayala, 2018; Confino, 2018; entre otros).

Este artículo hace foco en los sentidos que tuvo para los exiliados argentinos apelar a la figura del Núremberg desde una coyuntura temprana y cuando la "cuestión argentina" dificultosamente conseguía ser visibilizada internacionalmente como violación masiva y sistemática a los derechos y libertades fundamentales; pasando por el clímax del cerco internacional (1979-1981) al gobierno del general Jorge R. Videla - y cuando se acumulaban las condenas morales y políticas de actores del más diverso signo ideológico-; y hasta el ocaso del "Proceso de Reorganización Nacional" (PRN), cuando tras la derrota en la guerra de Malvinas y a punto de celebrarse las elecciones democráticas de octubre de 1983, el último presidente de facto el general Reynaldo Bignone intentó clausurar definitivamente cualquier "rendición de cuentas" de las FFAA por lo actuado en "la guerra contra la subversión", decretando la "ley de Autoamnistía" (Ley 22.924 de "Pacificación Nacional” (22/9/1983)1.

El trabajo parte de la hipótesis de que más allá de la heterogeneidad de actores del exilio que pusieron en circulación la noción de Núremberg entre 1976 y 1983, su sentido fue modificándose en los diversos contextos de lucha antidictatorial, pasando de ser un recurso comunicativo de traducción de la situación represiva argentina bajo el símbolo más universal del horror, hasta convertirla en una apelación doctrinal que permitía tipificar la desaparición forzada como crimen de lesa humanidad y por lo mismo imprescriptible, y en la forma en que los exiliados expresaron el descubrimiento del "juicio y castigo" - sea a partir de tribunales penales internacionales a la manera de los de Núremberg y Tokio de 1945, sea en tribunales argentinos y tras la caída del régimen militar - como nuevo horizonte de expectativas de su acción colectiva en el espacio público internacional.

Si bien los tres sentidos (estrategia de traducción, doctrina jurídica, juicio penal) se solaparon y convivieron a lo largo de toda la dictadura, resulta claro que desde el momento en que los militares comenzaron a diseñar dispositivos simbólicos y legales de clausura del "problema de los desaparecidos" (desde el último trimestre de 1979), las apelaciones de los exiliados al Núremberg se multiplicaron poniendo de relieve que ya no lo concebían sólo como un recurso eficaz de denuncia y para conseguir condenas

\footnotetext{
Boletín Oficial de la República Argentina, 27/9/1983.
} 
morales o políticas internacionales al régimen castrense, sino como el camino a transitar en pos de la persecución y punición de los culpables en sede judicial.

Finalmente, este artículo pretende mostrar que cuando el uso de la representación del Núremberg se extendió entre los exiliados argentinos, también se hicieron evidentes los desacuerdos y las disputas acerca de su significado ("venganza", "justicia popular", "justicia revolucionaria", "justicia de vencedores", "justicia independiente"), su alcance en términos de tramitación de las violaciones a los Derechos Humanos (DDHH) (memoria, autoconocimiento, castigo), la oportunidad de agitarlo o no en un contexto de promesa de liberalización y apertura política del régimen militar ("fantasma", "síndrome", "amenaza"), su posibilidad de concreción, tanto en términos de timing ("no habrá otro Núremberg", "Núremberg de nuevo") como de jurisdicción territorial (nacional o internacional).

\section{Los exiliados y el Núremberg como símbolo del horror. Uso pedagógico y ampliación de la solidaridad internacional}

Las primeras referencias al Núremberg fueron subsidiarias del esfuerzo del exilio por transnacionalizar la cuestión argentina, haciendo comprensible una realidad cultural que, por las contradicciones que parecía encerrar su historia política reciente, no despertaba la preocupación de la opinión pública internacional y los gobiernos de terceros Estados, ni la identificación como causa justa por parte de las agencias no gubernamentales del entramado humanitario global.

En el prólogo a la edición francesa de L'Argentine ou Le diable dans le soleil, el militante del Partido Revolucionario de los Trabajadores (PRT) y exiliado en París, Carlos Gabetta resumía algunas de las complejidades que a su juicio retrasaban el reconocimiento internacional de la grave situación que vivían los argentinos vulnerados en sus derechos más elementales:

"¿Cómo explicar, antes del golpe militar, que el gobierno que había decretado el estado de sitio, restaurado y aplicado la legislación represiva y creado las "Tres A" era el mismo que había sido votado por una abrumadora mayoría de argentinos? ¿Cómo precisar, después del golpe, que esos militares, en lugar de "poner orden", sólo habían oficializado y multiplicado la represión, que en realidad eran una continuación del último gobierno peronista, del cual se habían servido? ¿Cómo denunciar el terror, si en la Argentina se ha inaugurado la siniestra técnica de la desaparición de personas, si los presos no eran exhibidos en los estudios de fútbol, y si - a diferencia de lo que ocurrió en Chile - en nuestro país "la clase política" sólo había sido desalojada del poder, pero dormía en casa?" (Gabetta, 1983, p. 12). 
Jensen. Los exiliados argentinos y los sentidos del Núremberg: de recurso pedagógico a estrategia de persecución...

Si bien el esfuerzo exiliar por traducir, producir paralelismos y/o conceptualizar el régimen castrense no se agotó en conectarlo con el nazismo, lo cierto es que la matriz del Holocausto, del genocidio y también del antisemitismo fueron un recurso habitual para intentar posicionar el caso argentino en la esfera pública internacional y concitar una solidaridad transnacional esquiva que debía no sólo multiplicarse, sino comenzar a operar de manera eficaz en el aislamiento de la dictadura.

En este contexto y aunque los cuestionamientos a la insuficiencia de algunas de esas matrices simbólicas no faltaron y hubo preocupación porque la singularidad represiva argentina se diluyera por la instrumentalización de figuras (memoriales y jurídicas) culturalmente ajenas y distantes en el tiempo, la referencia al nazismo y en la misma línea al Núremberg, atravesaron comunidades, organizaciones, geografías y trayectorias exiliares muy diversas.

Pero si bien las referencias a la matriz del nazismo fueron un recurso pedagógico-político y de sensibilización transversal a las comunidades del exilio, fueron particularmente aquellas organizaciones de perfil humanitario del destierro argentino y las que hicieron una apuesta consciente por el multilateralismo solidario, y por el diálogo con interlocutores de la comunidad internacional (en particular las Naciones Unidas (NNUU), la Comisión Internacional de Juristas (CIJ), la Comisión Interamericana de Derechos Humanos (CIDH) de la Organización de Estados Americanos (OEA), el Congreso de los EEUU, el Movimiento Internacional de Juristas Católicos, Amnistía Internacional, Justicia y Paz, el Vaticano, Parlamento Europeo), las responsables de imponer la imagen del Núremberg para que se reconociera la masividad, sistematicidad y planificación de la represión desatada por el Estado terrorista, y se comprendieran las características específicas de su política de exterminio (los "desaparecidos" y los "campos de concentración").

En esa línea puede comprenderse el rol jugado por la Comisión Argentina de Derechos Humanos ${ }^{2}$ en la agitación del Núremberg. Para la CADHU, esta figura tenía un potencial ético-político capaz de producir una expansión de los límites de las obligaciones morales porque equiparaba la tragedia de los argentinos a la de las víctimas por excelencia de Occidente: las del genocidio nazi. En este sentido, la CADHU confiaba que hablar del Núremberg era una forma de convocar la solidaridad no sólo de los propios (sus compatriotas en el exilio y los pueblos latinoamericanos que sufrían el mismo drama), sino de gobiernos, estados, organismos internacionales y organizaciones transnacionales humanitarias con capacidades diferenciales de influencia y presión sobre la Junta militar.

\footnotetext{
2 Fundada a finales de 1975/principios de 1976, tras la muerte de sus principales referentes en el país, se perfiló como una organización humanitaria transnacional, con sedes en Madrid, París y Washington y presencia no orgánica en México, Holanda, Bélgica, Suiza y Suecia. Integrada en su mayoría por abogados penalistas y laboralistas (aunque también por artistas, intelectuales y periodistas), se presentó como una organización civil apartidaria, pese a que sus principales figuras eran reconocidos militantes del peronismo revolucionario y la izquierda marxista y trotskista (Gustavo Roca, Eduardo Duhalde, Lidia Massaferro, Rodolfo Mattarollo, Manuel Gaggero y Carlos González Gartland).
} 
Es así como una de las primeras referencias en torno a la figura del Núremberg como vector de internacionalización de la cuestión argentina la encontramos en una intervención de Rodolfo Mattarollo ${ }^{3}$ ante un auditorio presumiblemente compuesto por argentinos y otros latinoamericanos exiliados en París, en la que tras puntualizar que no venía sólo a traer "un relato de lágrimas y de sangre", y luego de equiparar a la Argentina con las dictaduras "neofascistas" y "terroristas" de Chile, Brasil y Uruguay -instaladas a "sangre y fuego" para mantener los "privilegios de una minoría sobre la inmensa mayoría dela población" -, sentenciaba que la "extensión de este sistema a toda una región, plantea otra vez la actualidad de un nuevo Núremberg como un desafío a la conciencia civilizada". ${ }^{4}$ Mattarollo parecía apelar a la memoria de la mayor tragedia de masas del siglo XX no sólo como forma de alertar sobre la reiteración de crímenes atroces en tierras lejanas, sino para convocar a sus compatriotas en el exilio a sumarse al movimiento de solidaridad para presionar al mundo "civilizado" a actuar - en este caso, y a diferencia del Holocausto - mientras el "exterminio no se haya consumado". En este sentido, Mattarollo reclamaba a la comunidad internacional y a las organizaciones humanitarias de alcance global, desarrollar "la solidaridad moral y material con los pueblos de Argentina y de América Latina", aportando "activamente al aislamiento de la Junta militar y los demás regímenes dictatoriales con medidas concretas en el plano económico, político, diplomático y cultural". ${ }^{5}$

¿Pero cómo desencadenar esa solidaridad a favor de "la libertad de presos políticos" y "desaparecidos", de "la devolución de sindicatos", de "la recuperación de derechos fundamentales y libertades democráticas" y del fin del "asesinato" y la "tortura" en Argentina? A su juicio, uno de los caminos era visibilizar aquello que aún no resultaba completamente evidente a la comunidad internacional, esto es, remarcar los parecidos de familia con el régimen condenado en Núremberg. En tal sentido, Mattarollo enfatizó que "no está en juego tan sólo la vida y la libertad del pueblo argentino [...] Ésta es la causa de todos los pueblos y los demócratas del mundo entero". En vísperas del Campeonato Mundial de Fútbol 1978 que se celebró en Argentina, Mattarollo afirmaba: "nuevos criminales de guerra han irrumpido en la escena internacional. Nuevos reos de

\footnotetext{
3 Fue miembro de la Asociación Gremial de Abogados de Buenos Aires junto a Ortega Peña, Eduardo Duhalde, Mario Amaya y Roberto Sinigaglia, integrantes de la primitiva CADHU. Su trayectoria de defensor de presos políticos se remontaba a la llamada "Revolución Argentina" (1966-1973) y a su rol como abogado de los sobrevivientes de la masacre de Trelew (agosto 1972). Militó en el PRT-ERP, integró la Junta Coordinadora Revolucionaria y dirigió Nuevo Hombre durante 1974. Se exilió en París donde integró la CADHU hasta 1979. También formó parte de la Comisión Internacional de Juristas con sede en Ginebra y fue uno de los promotores del Coloquio sobre Desaparición Forzada de Personas de París, que reunió a más de 500 juristas y reconocidas personalidades del campo humanitario internacional. Asimismo, fue una de las voces más reconocidas de la lucha antidictatorial argentina en foros como NNUU y en particular en la Comisión de DDHH, la Subcomisión de Prevención de la Discriminación y Protección de las Minorías y el Grupo de Trabajo sobre Desaparición Forzada de Personas e Involuntarias de Personas creado el 29/2/1980.

4 CADHU. Intervención de Rodolfo Mattarollo. París, sf. (Presumiblemente mayo 1978). Recuperado de: http:/eltopoblindado.com/agrupaciones/exilio/cadhu/ El subrayado es del autor

5 CADHU. Intervención de Rodolfo Mattarollo...
} 
Jensen. Los exiliados argentinos y los sentidos del Núremberg: de recurso pedagógico a estrategia de persecución...

delitos contra la humanidad han aparecido 40 años después de los nazis y de la guerra de España. Son los Videla y Pinochet...". ${ }^{6}$

\section{Los exiliados y el Núremberg como parte de la estrategia jurídica antidictatorial. De la doctrina de los crímenes imprescriptibles al "juicio y castigo"}

De la misma manera que las primeras apelaciones al Núremberg tuvieron que ver sobre todo con la necesidad de dar a conocer la magnitud represiva de la dictadura argentina por referencia a la masacre por excelencia, símbolo del horror para Occidente; la segunda forma de referir al Núremberg surgió como parte del perfeccionamiento de los repertorios de lucha exiliar para combatir los sofisticados recursos castrenses de neutralización de las condenas económicas, morales y militares que venían acumulándose. En tal sentido, referir al Núremberg pasó a ser parte del reforzamiento de la estrategia jurídica de acción exiliar, que desde la apelación al Derecho Internacional Humanitario buscaba identificar los crímenes cometidos por el Estado terrorista, para eventualmente punir a sus responsables.

Los exiliados comprendieron que el sistema desaparecedor - y su inocultable propósito de clausurar cualquier forma de investigación y castigo- volvía imperativo el recurso al Derecho Internacional Humanitario. En este contexto, encuadrar los crímenes de la dictadura bajo el paraguas de la Doctrina del Tribunal Militar Internacional de Núremberg, no sólo legitimaba la denuncia exiliar sobre la atribución de responsabilidad al Estado terrorista en la violación masiva, sistemática e indiscriminada de derechos protegidos por instrumentos humanitarios a los que Argentina estaba adherida, sino que colaboraba en encuadrarlos en una matriz simbólica que ponía en crisis las justificaciones castrenses ideadas para responder a la exigencia humanitaria de personalidades, partidos políticos, sindicatos, gobiernos, foros y organismos internacionales y organizaciones no gubernamentales.

Entre septiembre de 1979 y octubre de 1983, la dictadura desplegó una política sistemática orientada a dar "solución definitiva" al "problema de los desaparecidos". Esa política se sostenía en dos pilares complementarios: la promoción del olvido desde la escritura de una Historia oficial de lo ocurrido; y la puesta en marcha de un conjunto de estrategias pseudojurídicas que le permitieran levantar la principal "hipoteca" que pesaba sobre la continuidad del régimen, su imagen internacional y un eventual "ajuste de cuentas" por las violaciones a los DDHH perpetradas por los agentes y agencias del Estado terrorista. ${ }^{7}$

Así, en septiembre de 1979, la visita de la CIDH estuvo acompañada por un acalorado debate internacional sobre las llamadas "leyes sobre desaparecidos"

6 CADHU. Intervención de Rodolfo Mattarollo...

7 Días previos a la aprobación de las leyes sobre "desaparecidos", el diario El País (25/8/1979) señalaba: "Según comunican las agencias de prensa, el Gobierno argentino se dispone a levantar la hipoteca que para su imagen representa la cuestión de los "desaparecidos". No pudiendo resucitar a los muertos, opta por reconocer, para utilizar la cínica frase del general Roberto Viola, que esos hombres y mujeres permanecerán 'ausentes para siempre'"”. 
decretadas por el presidente Videla ${ }^{8}$; y calificadas por los exiliados como formas de "legalizar el genocidio", entendiendo que esas normas abrían el camino a la "posibilidad de que los desaparecidos ya no aparecieran nunca más y de que jamás se pudiera saber cuál había sido su verdadero destino". ${ }^{10}$ Como explicaba el corresponsal para América Latina de El País (6/9/1979), la intención de Videla de declarar legalmente muertos a los "desaparecidos" era expresión de aquello que "altos oficiales" manifestaban cuando desde el exterior se patrocinaban "campañas para exigir responsabilidades a los dirigentes castrenses: "no aceptaremos ningún Núremberg". ${ }^{11}$

Si las recomendaciones preliminares de la CIDH difundidas al finalizar la visita al país el 20 de septiembre de 1979 preocuparon al gobierno de Videla, entre esta coyuntura y la publicación del informe definitivo (mayo 1980), se sucedieron una serie de eventos que abrieron un debate complejo en las comunidades exiliares en torno al intento castrense de "borrón, pues y cuenta nueva"12 y en ese escenario multiplicaron las apelaciones al Núremberg.

El 27 de septiembre se difundía internacionalmente la noticia de la expulsión del periodista Jacobo Timerman, que pocos meses después publicó en EEUU las memorias de su secuestro, tortura, prisión política y salida del país tras sucesivos procesos ante la justicia militar y civil. En esas memorias, el ex director del periódico La Opinión, sentenciaba que "hoy los militares argentinos piensan en el tribunal de Núremberg no como un hecho histórico, sino como una posibilidad "y que "los asesinos argentinos tienen miedo. Y piensan en Núremberg" (Timerman, 1981, pp. 150 y 154).

Por su parte, el 12 de octubre, la CADHU organizaba una conferencia de prensa en la Asamblea Nacional Francesa en la que tres sobrevivientes de la Escuela de Mecánica de la Armada (ESMA) (Ana María Martí, Alicia Miliá de Pirles, Sara Solarz de Osatinsky) daban su testimonio sobre el "proceso de exterminio masivo que se vivió y vive aún en Argentina" (CADHU, 1979, p. 8). Atentas a los efectos de señalar que el destino de la mayoría de los detenidos-desaparecidos era la muerte, las "liberadas" de la ESMA se asumían como "testigos de cargo ante el pueblo argentino, la opinión pública internacional y ante todos los Tribunales que juzguen a los responsables del genocidio argentino" (CADHU, 1979, p. 9).

\footnotetext{
8 El exilio peronista en Barcelona afirmaba: "Durante los últimos meses el gobierno pareció, por momentos, un gladiador obnubilado. ¿No fue un golpe de ciego el burdo intento de una "solución final” al problema de los desaparecidos, a través de los decretos de septiembre? ¿Podrían haber pergeñado los amanuenses de la Junta un engendro jurídico más infortunado y más idóneo para levantar un huracán de protestas?”. “Argentina: el síndrome de Núremberg”. Testimonio Latinoamericano, Barcelona, año I (1), marzo/abril 1980, 3-6.

9 "Por la libertad de los desaparecidos. Contra la legalización del genocidio en la Argentina" fue la consigna central de una concentración unitaria de exiliados frente a la embajada argentina en Madrid el 6 de septiembre de 1979. Presencia Argentina, Periódico del Centro Argentino de Madrid, año 1 (1), octubre 1979, p. 1.

${ }^{10}$ Lopez Acotto, A. “Asesinato de la esperanza”. El País, 30/8/1979. La cursiva es del autor.

${ }^{11}$ De la Calle, Á. "La OEA investiga las violaciones de los derechos humanos en Argentina”. El País, 6/9/1979.

${ }^{12}$ Schmucler, H. "Actualidad de los derechos humanos". Controversia, México, año I (1) octubre 1979, p. 3.
} 
Jensen. Los exiliados argentinos y los sentidos del Núremberg: de recurso pedagógico a estrategia de persecución...

Mientras la Junta anunciaba el inicio de un nuevo tiempo político, tras la publicación de las "Bases Políticas para el Proceso de Reorganización Nacional" (diciembre de 1979), Luis Bruschstein Bonaparte explicaba que el exilio en su condición de "fiscal" debía exponer ante la opinión pública internacional la gravedad de la situación argentina, asumiendo la bandera de los DDHH "sin abstracciones ni equidistancias". Desde la radicalidad de la consigna de las Madres de Plaza de Mayo -"que aparezcan con vida los desaparecidos" -, Bruschstein Bonaparte afirmaba que no bastaba con conocer la magnitud de la tragedia, sino que para que "no se repitan nunca más estas aberraciones "era necesario "el castigo ejemplar a los responsables". ${ }^{13}$

En el mismo número de la revista Controversia, el ex diputado peronista Héctor Sandler ${ }^{14}$ consultado sobre el "diálogo político" que pretendía inaugurar el régimen castrense, puntualizaba que "cuando los militares hablan de acuerdo cívico-político, quieren tapar el problema de la masacre" (1979, p. 6). Para Sandler, era condición sine qua non un Núremberg. Frente a la pregunta de Luis Bernetti acerca de qué entendía por Núremberg, Sandler explicaba: "Darse cuenta, como se dio cuenta la sociedad alemana, que con el asesinato no se puede convivir" (1979, p.5). Consultado ante la oportunidad de agitar la bandera del Núremberg, Sandler planteaba dos cosas. La primera que no se podía avanzar en un "acuerdo político sin darle explicación al padre o la madre que le falta el hijo". La segunda, que si no se visualizaba en la Argentina (pueblo y políticos) quién pudiera hacerle "lavar la ropa" al Ejército, entonces era porque "la solución argentina está más lejos de lo que se piensa" (1979, p.5).

Un par de meses después, Schmucler volvía a ocuparse del tema de los DDHH en las páginas de Controversia (1980, año I, nº) para discutir la relación entre "la Argentina de adentro y la Argentina de afuera". En este artículo, tras señalar las diferencias sustantivas entre las dos Argentinas, - "la que parece dispuesta a enterrar en el olvido, sin mayor trámite, esta historia de infeliz recuerdo y cerrar de una vez las heridas que la guerra infligió al entramado social"; y la que "se muestra todavía incapaz de dar sepultura a ese pedazo de historia sin enterrarse a sí misma" (1980, p. 4) -; Schmucler sentenciaba: "en la Argentina, al menos por largo tiempo, no habrá otro Núremberg" (1980, pp. 4, 5). Schmucler no consideraba que los crímenes no reclamaran juico y castigo. Pero tras señalar que mientras en el exilio los DDHH evocaban "la muerte" y en la "Argentina de adentro", son "la posibilidad de existir, de ser personas y protagonistas, mientras el terror de estado se ejerce para impedirlo" (1980, p. 5), explicaba que un Núremberg como "justicia del pueblo" ("de los oprimidos") era imposible porque no existía "la fuerza para imponerlo" (1980, p. 5).

A juicio de Schmucler, agitar la "bandera" de un Núremberg cuando no era "posible como objeto de acción política" era no sólo "contraproducente", sino que podía llevar una "parálisis". Pero "parálisis", ¿para qué? o ¿para quiénes? Schmucler no parecía preocupado tanto por el proceso de apertura política al que se refería Sandler, sino por la radicalización del divorcio entre los exiliados y "la Argentina de adentro":

13 "Derechos humanos: sin abstracciones ni equidistancias". Controversia, año I, diciembre 1979, pp. 2-3.

${ }^{14}$ Héctor Sandler. "La larga marcha del aramburismo al peronismo". Controversia, año I, diciembre 1979, pp. 2-3. 
"Hoy, los derechos humanos en la medida en que su agitación en el exterior pueda evocar un pasado que se quiere borrar corre el riesgo de volverse el signo de lo otro, lo enemigo. En la Argentina de adentro el tema dominante no es el de los derechos humanos como lo entendemos en el exilio [...] Es obvio que no postulo abandonar la actividad exterior por el respeto a los derechos humanos en la Argentina: se trata de afinar los objetivos para que el pueblo se sienta identificado con ella" (1980, p. 5).

Desde la lógica de Schmucler, el Núremberg como consigna - y no como horizonte - debía ser descartado como parte del "esfuerzo" del exilio para que sus “temas" fueran los del "país de adentro" (1980, p. 4).

Mientras la Comisión de Derechos Humanos de NNUU creaba un Grupo de Trabajo sobre Desapariciones Involuntarias y Forzadas de Personas (29/2/1980) y se publicaba el Informe final de la visita de la CIDH a la Argentina (abril 1980) -, al que el Ministro del Interior Albano Harguindeguy respondió que "consideraba definitivamente cerrado el expediente de los desaparecidos por razones políticas" ${ }^{\text {"15_; }}$ los debates exiliares en torno al Núremberg se recalentaron. Desde México, Susana Aguad preguntaba a Schmucler ¿cuál era "capítulo cerrado para la mayoría de los argentinos"? Y sentenciaba que si se refería "al destino de los hijos de esas madres cuyas detenciones nunca fueron reconocidos oficialmente" y por los se alzaban voces en Argentina y el mundo, el camino era uno: "Ni olvido, ni venganza: JUSTICIA". ${ }^{16}$

Por su parte, mientras la Junta publicaba su contrainforme a la visita a la CIDH (Junta Militar, 1980), fijando la historia oficial de lo ocurrido en el país, Álvaro Abós se preguntaba " ¿Qué le sucede a este Poder Carnívoro habituado a deglutirse con apetito cuanto obstáculo se le pusiera delante? ¿Qué mal lo carcome?" ${ }^{17}$ Desde Testimonio Latinoamericano diagnosticaban que el régimen militar -cercado por condenas y denuncias de un Occidente donde la "defensa de los DDHH se ha inflado como un globo inmenso" - y "perturbado" por "el castigo a los torturadores de Irán, el juicio político que los legisladores bolivianos incoan a Banzer, la discusión de una amnistía en Brasil (que al final amparó a torturadores)", sufría el "síndrome de Núremberg":

"La duda hamletiana (cómo blanquear las conciencias, cómo lavar la sangre vertida, cómo disipar el horror) nubla la mente de los gobernantes, desquicia su equilibrio. En su sueño agitado palpita una visión que el régimen, quizás, aún no se anima a contemplar. Clara como un diamante, esa visión es la del futuro inevitable: sea cual sea la solución que se encuentre, haya o no haya Núremberg, el poder usurpado habrá de ser devuelto". ${ }^{18}$

\footnotetext{
${ }^{15}$ El País, 9/5/1980.

${ }^{16}$ Aguad, S. "Ni olvido ni venganza: JUSTICIA". Controversia, año II (6), mayo, 1980, p. 5

17 "Argentina, el síndrome de Núremberg". Testimonio Latinoamericano, Barcelona, año I (1), marzo-abril, 1980 , p. 6.

18 “Argentina, el síndrome...", p. 6
} 
Jensen. Los exiliados argentinos y los sentidos del Núremberg: de recurso pedagógico a estrategia de persecución...

Entre mediados y finales de 1980 parecía evidente que la convocatoria de Videla al "diálogo político" y el límite impuesto de no revisión de la actuación de las FFAA en la "guerra contra la subversión", implicaba dejar a los "desaparecidos" en el pasado. En este contexto el debate acerca de la estrategia de denunciar el "genocidio", explicitando como lo hicieron las sobrevivientes de la ESMA que la mayoría de los secuestrados que pasaron por Centros Clandestinos de Detención (CCD) estaban muertos o reclamándolos con vida ${ }^{19}$, dio nuevos sentidos al Núremberg. Sentidos que no fueron ajenos a la revisión de las prioridades de la lucha antidictatorial frente al nuevo tiempo político que el llamado al "diálogo" parecía abrir y en la perspectiva de una más o menos cercana convocatoria a elecciones.

Así en julio de 1980, Osvaldo Pedrozo reavivando el debate con Schmucler ${ }^{20}$, lo acusaba de plegarse al "inaceptable blanqueo que propone la Junta" y a aquellas voces que livianamente afirmaban que "esos miles y miles de militantes no están desaparecidos, sino muertos (declaración de Ricardo Balbín en la TV española, 13/4/1980)". ${ }^{21} \mathrm{Y}$ aunque coincidía con Schmucler en que no había aún en el país "fuerza suficiente para imponer [...] un Núremberg"; a su juicio, el exilio debía acompañar a los partidos políticos que se atrevían a incluir en un documento conjunto "el reclamo por el esclarecimiento de la situación de los desaparecidos". Según Pedrozo, era "moral y políticamente inaceptable" dar por muertos a los desaparecidos", como era inadmisible "borrar el pasado". ${ }^{22}$ Porque aunque "no es posible derrocar [la dictadura] con la movilización de masas e imponer una justicia revolucionaria", la alternativa no era modificar el lenguaje (evitando la referencia al Núremberg), sino luchar porque "la ineludible negociación sea lo más beneficiosa posible a los intereses de nuestro pueblo". ${ }^{23}$

Entre diciembre de 1980 y los primeros meses de 1981, la cuestión de los testimonios de los sobrevivientes de los CCD como "prueba" de la "muerte"/"presunta muerte" de los "desaparecidos" y de la naturaleza "genocida" de la Junta militar ${ }^{24}$, volvió a poner en el centro de la escena la cuestión de qué hacer con ese pasado-presente

\footnotetext{
${ }^{19}$ En abril de 1980, Pancho Carricaburu volvía sobre el testimonio de las sobrevivientes de la ESMA y lo ligaba a la urgencia del régimen militar y al impulso del Departamento de Estado de los EEUU de "cerrar el escándalo" de los "desaparecidos". Carricaburu marcaba la diferencia entre reclamarlos vivos o muertos en términos de una posible revisión de cuentas: "Con el informe de las tres mujeres "liberadas para que colaboren con el régimen en el exterior", como ellas mismas dicen, se denuncia que los desaparecidos eran asesinados y se va más lejos aún, al decir que esa fue la suerte corrida por la totalidad. Objetivamente -sea cual fuere la convicción de las ex prisioneras- se da lugar a la creencia de que ya no hay más que reclamar, de que el episodio de los desaparecidos pertenece al pasado y que hay que continuar la lucha recordándolos pero pasando a otra cosa. Carricaburu, P. "Argentina: desaparecidos". Comunidad, Estocolmo, (18), 20/4/1980, p. 7.

${ }^{20}$ Controversia, febrero, 1980, año I, $\mathrm{n}^{\circ} 4$.

${ }^{21}$ Pedrozo, O. "El inaceptable blanqueo que propone la Junta". Controversia, año II (7), julio 1980, p. 14.

${ }^{22}$ Pedrozo, O. "El inaceptable blanqueo...", p. 15.

${ }^{23}$ Pedrozo, O. "El inaceptable blanqueo..., p. 15.

${ }^{24}$ Schmucler resaltaba la centralidad de los testimonios "sobre los campos secretos de detención en Argentina" porque "nada puede condenar a la Junta militar respecto al respecto del golpe de 1976, como estas narraciones de horror". "El testimonio de los sobrevivientes". Controversia, año II (9-10), diciembre 1980, p. 4.
} 
violento en términos de justicia. Sin entrar en el análisis pormenorizado del debate entre Héctor Schmucler y Mempo Giardinelli ${ }^{25}$, quiero destacar algunas de sus opiniones respecto al Núremberg.

Retomando la cuestión de las diferencias entre la "Argentina de adentro" y la "Argentina de afuera" a la hora de entender los DDHH, Schmucler señalaba que reconocer sin ambages que los "desaparecidos" estaban muertos en nada afectaba la inevitable "rendición de cuentas" que la sociedad argentina pediría - "aunque no será hoy ni mañana" - "por la forma en que fueron liquidados miles de sus miembros". ${ }^{26}$ Una "rendición de cuentas" que el filósofo cordobés exiliado en México había asimilado a un Núremberg.

Tras señalar que "no hay nada más crítico que el tema de los desaparecidos. Mejor dicho de la presunta muerte de los desaparecidos"27, Giardinelli enfatizaba la importancia que tenía luchar por ellos considerándolos "vivos" en orden a una "rendición de cuentas". El escritor enfatizaba que "no es lo mismo "pedir cuentas" por los muertos de ayer, que reclamar y exigir la aparición con vida - o la explicación de su muerte - y la sanción de los responsables de los desaparecidos de hoy" (1981, p. 100). Para Giardinelli, la consigna "aparición con vida" lejos de ser una bandera agitativa daba cuenta de la urgencia de no desamparar ni olvidar a "a ese solo sobreviviente que posiblemente aun este siendo torturado, que tiene un nombre y apellido" (1981, p. 100). Y, al mismo tiempo era el recurso para mantener viva "la conciencia criminal de los torturadores y de los responsables de los torturadores". Esto es, mostrarles que "no vamos a dejar dormir tranquila a la Junta Militar" (1981, p. 100).

Para Giardinelli, "justicia” era en primer lugar "no olvidar, volverlos locos con la culpa, con la señalización permanente” (1981, p. 100). Quizás porque era escéptico sobre un escenario de persecución penal promovido por los futuros gobernantes argentinos. A su juicio, lo más probable era que los civiles electos priorizaran la "reconciliación, la pacificación, no hurgar en el pasado" a un eventual "pedido de cuentas". O que dijeran: "aquello pasó hace años" y "fue una guerra sucia y el trabajo sucio que le tocó a Videla" (1981, p. 100).

Para el escritor exiliado en México, valía más exponer la actualidad de la tragedia y mantener viva la memoria del compromiso institucional de las FFAA con la represión, que trabajar en pos de la condena penal de ex gobernantes en un futuro incierto. En tal sentido, Giardinelli afirmaba: Videla, Massera y Agosti "no serán juzgados (no pienso necesariamente en un Núremberg, cabe aclararlo") porque para cuando la justicia pueda operar, ya no estarán al mando de sus fuerzas: "Cuando se les pida cuentas estarán ancianos, jubilados o muertos" (1981, p. 100).

Durante el primer trimestre de 1981, una sucesión de eventos tales como la reunión del Coloquio Internacional sobre Desaparición Forzada de Personas de París (31/1-1/2/1981) y el Primer Congreso Latinoamericano de Familiares de Desaparecidos

${ }^{25}$ Giardinelli, M. "Los sobrevivientes de los testimonios". Cuadernos de Marcha, México, (11), enerofebrero 1981.

${ }^{26}$ Schmucler, H. "El testimonio de los sobrevivientes". Controversia, año II (9-10), diciembre 1980, p. 5

${ }^{27}$ Giardinelli, M. "Los sobrevivientes...", p. 98. 
Jensen. Los exiliados argentinos y los sentidos del Núremberg: de recurso pedagógico a estrategia de persecución...

organizado por Fundación Latinoamericana por los Derechos Humanos y el Desarrollo Social (FundaLatin) en San José de Costa Rica (enero 1981), y las conmemoraciones en las principales capitales de la diáspora (México D.F., Madrid, París o Barcelona) del $5^{\circ}$ aniversario del golpe de Estado en Argentina, pusieron en evidencia que cuando los exiliados hablaban del Núremberg pensaban en definir una estrategia jurídica que, sea al amparo del Estatuto del Tribunal Militar Internacional de 1945 sobre "delitos de lesa humanidad", sea desde la redacción de una convención internacional sobre desaparición forzada e involuntaria de personas ${ }^{28}$, les permitiera seguir luchando en pos del juicio y castigo a los culpables.

El exilio encaraba este nuevo escenario nacional e internacional consciente de que el recambio de la titularidad del Ejecutivo en Argentina (el general Viola sustituía a Videla) y la imagen que el ex Jefe del Ejército buscaba proyectar de hombre moderado llamado a reconducir al país a la normalidad democrática ${ }^{29}$, no hacían sino profundizar la estrategia de "lavado de cara (y de manos) del régimen"30 y su insistencia en dejar atrás la pesada herencia de violaciones sistemáticas a los DDHH.

Asimismo, los desterrados reconocían que los éxitos cosechados ante organismos internacionales humanitarios y organizaciones no gubernamentales no eran pocos, aunque el camino no se percibía libre de escollos. Era claro que el lapidario informe de la $\mathrm{CIDH}$ no había tenido los efectos esperados en términos de aislamiento de la dictadura en tanto que a último momento la $10^{\mathrm{a}}$ Asamblea de la OEA no condenó abiertamente al régimen militar argentino ${ }^{31}$. Por otro lado, el ascenso del republicano Ronald Reagan a la Casa Blanca (enero 1981) hacía prever que ya no soplarían buenos vientos para el humanitarismo global, pese a que el primer año de labor del Grupo de Trabajo de Desaparición Forzada de NNUU había arrojado información sustantiva sobre la grave situación de miles de personas detenidas y desaparecidas en Latinoamérica, con especial referencia al caso argentino.

${ }^{28}$ Recordemos que desde el Coloquio de París y en particular en los tres Congresos Latinoamericanos de Familiares de Detenidos Desaparecidos (San José de Costa Rica (enero 1981), Caracas (noviembre de 1981) y Caracas (junio 1982)) se discutieron ponencias y documentos que culminaron con la redacción de un anteproyecto de Convención Internacional sobre Desaparición Forzada de Personas.

${ }^{29}$ En esa línea, durante su visita a los EEUU, el presidente Viola declaraba su preocupación por el "asunto de los desaparecidos" de cara al reanudamiento de la venta de armas a la Argentina. Interrogado por la prensa, Viola puntualizó que la investigación no incluiría a las fuerzas de seguridad, porque "A los vencedores no se les investiga". Ejemplo de la amplitud del debate en torno al Núremberg, el presidente señaló: "Si Alemania no hubiera perdido la guerra, el juicio habría tenido lugar en Virginia", refiriéndose probablemente al juicio de Núremberg" (Vilaro, R. "Reagan: pleno apoyo norteamericano a Argentina". El País, 19/3/1981.

${ }^{30} \mathrm{Al}$ conocerse quién sería el reemplazante de Videla, la Casa Argentina en Catalunya alertaba que ante la ausencia de explicaciones acerca de los "desaparecidos", las denuncias de nuevos secuestros, la persistente condición de los detenidos a disposición del Poder Ejecutivo sin causa ni proceso, la no eliminación de los tribunales militares y el no restablecimiento de los derechos sindicales y políticos, el cambio de titularidad del Poder Ejecutivo Nacional sólo era un cambio cosmético. Casa Argentina en Catalunya. "Declaración", febrero 1981. Sugerimos la lectura del último libro de Marina Franco (2018) de cara a comprender los modos en que los gobiernos dictatoriales enfrentaron desde el mediodía del "Proceso" las consecuencias de la guerra contra la subversión".

${ }^{31}$ El Pais, 28/11/1980. 
En este contexto se multiplicaron los esfuerzos de diferentes organizaciones humanitarias argentinas o en las que activaban exiliados argentinos en España, Francia, México, Italia, Suecia, Venezuela (CADHU, Comisión de Familiares de Presos y Desaparecidos en la Argentina (COSOFAM) la Federación Latinoamericana de Asociaciones de Familiares de Detenidos Desaparecidos (FEDEFAM), entre otras) para que la desaparición forzada fuera tipificada como "crimen internacional" y "contra la humanidad", esto es como delito "masivo", "sistemático", "racional", "administrativo", "imprescriptible", "no amnistiable" ni "extraditable" y de "responsabilidad penal individual" (incluyendo dirigentes, organizadores, instigadores y cómplices), de "juzgamiento internacional" y en el que no podía invocarse el cumplimiento de "actos de Estado", ni la "obediencia debida".32

Trabajar para que las condenas políticas y morales acumuladas tuvieran consecuencias jurídicas implicó para el exilio argentino o bien explorar el potencial punitivo de viejos instrumentos como el Estatuto del Tribunal de Núremberg, o bien apostar por ampliar el ordenamiento internacional vigente para dar cabida a un delito de nuevo cuño que requería, de un nuevo régimen de prueba, más allá de que compartía con el "delito de genocidio" su condición de desafío a la responsabilidad internacional (FundaLatin, 1982).

Más allá de los debates al interior de las redes humanitarias transnacionales, ${ }^{33}$ los exiliados argentinos entrevieron que estas vías legales para perseguir y punir penalmente a los represores argentinos no eran incompatibles o como mínimo ambas pretendían efectivizar aquello que proclamaban las consignas exiliares en el contexto de la conmemoración del $5^{\circ}$ aniversario del golpe de Estado. Así lo manifestaba, Lidia Massaferro en el acto organizado por la CADHU en Madrid:

"No hay ni habrá borrón y cuenta nueva. Por el contrario.

Memoria y cuenta del dolor del pueblo y de las víctimas

\footnotetext{
${ }^{32}$ Sobre la tipificación del delito de desaparición forzada, véase los debates en el Coloquio de París y en los tres congresos de Familiares de Desaparecidos de San José de Costa Rica y Caracas.

${ }^{33}$ Para comprender algunos de los términos del debate acerca de Convención sí o Convención no y sobre los diversos posicionamientos acerca de lo que había significado el Tribunal de Núremberg ("justicia a secas" o "justicia de vencedores"/"justicia revolucionaria"), veánse las reflexiones del penalista argentino Roberto Bergalli en el congreso de FundaLatin de Caracas de noviembre de 1981: "Imprevistamente - para quienes descontaban por anticipado y eran conscientes que cualquier convención de este tipo que encierre sanciones aplicables a los gobiernos que amparan esos hechos y a los autores de tales desapariciones, sólo puede aplicarse en el futuro - fue introducida la discusión sobre una supuesta retroactividad de las leyes penales. Quienes sostenían esa última posibilidad alegaban peregrinamente que si el reclamo por un derecho nuevo debía formularse desde las posiciones de quienes siempre han sido sojuzgados, era justo que esa convención, dictada bajo la presión superior del triunfo del pueblos y grupos sociales antaño sometidos (como son los latinoamericanos) pudiera venir a juzgar hechos del pasado, tal como los supone una verdadera revolución. Se replicó esta argumentación que emplear una tesis semejante, [...] era incurrir en el mismo comportamiento observado por los militares genocidas de los pueblos latinoamericanos, era caer en el mismo error cometido por los redactores del Estatuto de Núremberg -que en la guerra crearon un derecho para juzgar hechos ocurridos en el pasado, los cuales eran absolutamente punibles bajo el sistema jurídico vigente para el territorio en que aquellos se concentraron - y era institucionalizar la incertidumbre jurídica" (Bergalli. R. "Coloquio Internacional de Desaparición Forzada de Personas". Resumen de Actualidad Argentina (57), 11/1/1982, p. 9).
} 
Jensen. Los exiliados argentinos y los sentidos del Núremberg: de recurso pedagógico a estrategia de persecución...

directas. Memoria y cuenta de los asesinos, torturadores y explotadores. Memoria viva que se funda en la justicia. Habrá Núremberg, habrá investigación, habrá reparación de tanto escarnio. La potencialidad de un pueblo que no han conseguido castrar lo garantiza. ¡Abajo la dictadura militar genocida! ¡ La sangre derramada no será negociada! ¡Libertad, Justicia y Democracia para Argentina!” (Amorós, 2011, p. 381).

En un escenario donde el "castigo a los culpables" y la "vindicación de justicia" comenzaba a ser para los exiliados argentinos algo más que señalar a los represores y mantener vivo el recuerdo de sus crímenes y de sus víctimas, para incluir también la aspiración a perseguirlos y condenarlos en un futuro más o menos cercano en territorio argentino o bajo jurisdicción internacional como lo hicieron los tribunales de la segunda posguerra mundial; el Núremberg operó tanto como un llamado de atención a la consciencia ética del mundo ante la reedición de la barbarie renacida en América Latina bajo la forma del crimen de la desaparición forzada ${ }^{34}$, como aquel "fantasma" 35 que venían agitando para mostrarle a los perpetradores que al igual que los jerarcas nazis no escaparían de los estrados judiciales.

Como señalaba FundaLatin, "la reiteración, la magnitud y la institucionalización de la práctica del desaparecimiento en varios países del continente constituyen un hecho que justifica la constitución de un tribunal para que juzgue y castigue a esos delincuentes". Para los exiliados, la asignación de responsabilidades penales era una piedra basal para la futura democracia argentina: "porque la impunidad de los delitos - especialmente cometidos contra los débiles - destruye las formas elementales de solidaridad". ${ }^{36}$

Las referencias al Núremberg acompañaron la denuncia exiliar hasta el final del PRN. Si desde los primeros anuncios de constitución de la Multipartidaria y ante el

\footnotetext{
${ }^{34}$ Mientras se celebraba el II Congreso de Familiares de Desaparecidos en Caracas, la organización ecuménica humanitaria FundaLatin afirmaba: "Nadie pudo imaginar que sólo un cuarto de siglo después de la sentencia del Tribunal de Núremberg, fuera necesario reponerlas porque un fenómeno similar azotaría a un continente". Y concluía: "Cierto es que Los mismo autores que han cometidos estos actos desde el poder omnímodo se protegen y se auto-otorgan amnistías de modo que parece lejana la acción de la justicia. Pero ésta, aunque tarde, siempre llega" (pp. 12-13). FundaLatin (noviembre 1982). "Núremberg de nuevo". FundaLatin Solidaridad, No Especial sobre el II Congreso Latinoamericano de Familiares de detenidos-desaparecidos. Archivo Nacional de la Memoria. Bs As. Caja 24. Otras instituciones.

${ }^{35}$ En agosto de 1981, la revista Proceso de México recogía las declaraciones de Ana María Martí de marzo de ese año ante la BBC de Londres (Hora, R. "Un Núremberg contra torturadores en la BBC de Londres", 17/8/81, p. 41). La sobreviviente de la ESMA recordó lo que les gritaban los torturadores en aquel CCD: "morirás, me dijo muchas veces el capitán. Todos aquí van a morir porque no permitiremos que haya otro Núremberg". Si la memoria de las condenas del Tribunal militar de la ciudad alemana formateó la modalidad represiva elegida por los militares argentinos, hay que señalar que la visita de Martí, Solarz y Susana Burgos a Inglaterra formó parte de una investigación llevada a cabo por la televisión inglesa sobre las complicidades del gobierno británico con la dictadura argentina (venta de armas) y a la vez con una operación de "escrache" a varios represores argentinos que habían operado en la ESMA y que por entonces ocupaban cargo en la agregaduría naval de la embajada argentina en Londres. Con esto queremos indicar que la justicia exiliar tenía formas diversas.

${ }^{36}$ FundaLatin (noviembre 1982). "Núremberg de nuevo", p. 13.
} 
llamado al diálogo político, los exiliados reconocían que los "criminales no escaparán a su juicio, $[\ldots]$ no habrá olvido ni perdón" ${ }^{37}$; durante la guerra de Malvinas, desde su exilio en México Héctor Sandler recuperó los "principios de los procesos de Núremberg" para que la comunidad internacional se responsabilizara de "frenar el crimen de guerra" (la "invasión de las islas"), a sabiendas de que la Junta militar argentina operaba "por el temor a perder el poder que usurpó en 1976".38

Si desde que la dictadura militar se propuso hacer política en tiempos de Videla, la clausura del "problema de los desaparecidos" fue un objetivo explícito para el régimen, en la coyuntura de fracaso y derrumbe tras la derrota en la guerra de Malvinas evitar cualquier forma de revisión de lo actuado por las FFAA en la "guerra contra la subversión" se impuso como un límite infranqueable, del mismo modo que pareció ser el único acuerdo al interior de las FFAA.

Si tempranamente los exiliados habían denunciado cada intento oficial de clausurar el pasado, entre la guerra de Malvinas y la celebración de las elecciones democráticas, la referencia al Núremberg estuvo asociada específicamente a la lucha contra la impunidad. En el $6^{\circ}$ aniversario del golpe de Estado, desde Madrid, Gustavo Roca volvía a señalar que "el fantasma de un Núremberg pesa demasiado sobre la conciencia culpable de las Fuerzas Armadas. De allí que la exigencia de un seguro de impunidad será tan imperativa como imposible". ${ }^{39}$

Tras la derrota de Malvinas, el último presidente de facto sancionó la "Ley de Pacificación Nacional" o de "Autoamnistía". Los exiliados volvieron a denunciar como lo habían hecho con la publicación del "Documento Final" de la Junta militar (abril 1983) que se estaba frente a un intento de "solución final" sobre el "genocidio" más grande de la historia argentina. Pero en esta ocasión a través de un instrumento "legal" que concentró todo el repudio de los exiliados convencidos de que en Argentina era inviable la impunidad. Esto es, como había señalado Gustavo Roca en vísperas de la guerra de Malvinas, que "más allá y por encima de toda imposición que se selle y de todo contrato que se firme, está la voluntad popular que exigirá una investigación y que impondrá, tarde o temprano, el justo castigo a los responsables del genocidio de nuestro pueblo y de la depredación de nuestro país". ${ }^{40}$

Pocos días antes de las elecciones presidenciales y mientras el exilio recordaba que era necesario que se cumplieran ciertos "requisitos mínimos" para que existan "Estado de derecho y "democracia", el debate en torno a la nulidad de la ley de "Autoamnistía" volvía a convocar a la doctrina y a la escena judicial del Tribunal de Núremberg.

\footnotetext{
${ }^{37}$ Movimiento Independiente (Lista Dos) de la CAS. (1981). "El país, el exilio, la CAS, México", noviembre. En: Bernetti y Giardinelli, 2003, p. 224.

${ }^{38}$ Sandler, H. (1982). "La responsabilidad de los dirigentes". México: Democracia y Libertad Edits., mayo. Archivo Nacional de la Memoria. Caja 28, Carpeta 1982, pp. 5-6.

39 “A seis años vista". Resumen de Actualidad Argentina (62), 22/3/1982, p. 34.

40 “A seis años vista”..., pp. 34-35.
} 
Jensen. Los exiliados argentinos y los sentidos del Núremberg: de recurso pedagógico a estrategia de persecución...

Por una parte, el abogado penalista y ex Procurador del Tesoro de la Nación, Enrique Bacigalupo no sólo mostraba que jurídicamente "la ley" carecía de validez y su anulación no ponía en riesgo la "seguridad jurídica", sino que apelaba a la doctrina Núremberg para cuestionar los rumores de aplicación del principio de "obediencia debida". Ante declaraciones del candidato del radicalismo Raúl Alfonsín al diario La Voz $(13 / 8 / 83)$ en las que señalaba la necesidad de distinguir entre las responsabilidades de los que "tomaron las decisiones sobre los métodos de lucha" y los que las cumplieron; el penalista exiliado en Madrid advertía que "nadie está obligado a obedecer órdenes cuyo cumplimiento implique la comisión de un delito [...] Esto ya quedó claro en el proceso de Núremberg y hoy pertenece a la consciencia jurídica universal". ${ }^{41}$

Pero mientras Bacigalupo recurría al cuerpo de doctrina internacional humanitaria de Núremberg para bloquear el camino de una "justicia a medias", Víctor Mate planteaba desde las páginas de Resumen de Actualidad Argentina que si "hacer justicia [...] es una obligación para Argentina, como para toda la humanidad", sería "miope" pensar que con un Núremberg se podría evitar que la ESMA se repitiera. Mate explicaba que siendo un tribunal de "legitimidad dudosa que cojeaba de una pata, ya que también Hiroshima se nos presenta como una patética realidad", el tribunal alemán fue una "pizca de justicia". Desde Madrid, Mate reclamaba a los argentinos seguir la senda de Fromm, Horkheimer, Marcuse y Adorno que postularon que para que la historia no se repitiera era necesario explicar el porqué del fenómeno criminal del nazismo como "única forma de controlar las causas en el futuro". ${ }^{42}$

En el mismo número en que se comunicaban los resultados de las elecciones argentinas del 30 de octubre de 1983, Resumen de Actualidad Argentina publicaba el comentario de Marcelo Montenegro sobre la "Autoamnistía militar". Tras analizar detalladamente el articulado de la ley en lo relativo a la extinción de acciones penales para culpables de delitos cometidos en orden a "prevenir, conjurar o poner fin a las actividades terroristas o subversivas", Montenegro resaltaba que los militares quisieron al mismo tiempo "instrumentar un pesado manto de olvido" e "inhibir la prosecución de juicios como los que se han iniciado a Videla, Massera, Harguindeguy y etc., y a cubrirse las espaldas respecto a futuras investigaciones parlamentarias, constitución de tribunales especiales o cualquier otra forma que pueda revestir el Núremberg que temen". ${ }^{43}$ En tal sentido, para los exiliados alentar el "fantasma del Núremberg" era la forma de exigir "juicio y castigo", sean cuales fueran sus valoraciones acerca de la eficacia y naturaleza del Tribunal que juzgó y condenó a más de una veintena de jerarcas nazis entre noviembre de 1945 y octubre de 1946.

\footnotetext{
${ }^{41}$ Sánchez, S. y Bacigalupo, E. "Estado de derecho, amnistía y deuda externa". Resumen de Actualidad Argentina (96), 24/10/1983, p. 24.

${ }_{42}$ Mate, V. "Un medio para erradicar la tortura". Resumen de Actualidad Argentina (96) 24/10/1983, p. 37.

${ }^{43}$ Montenegro, M. "Comentario sobre la ley de "autoamnistía"”. Resumen de Actualidad Argentina, no 97, 7/11/1983, pp. 25.
} 


\section{A manera de cierre}

Este artículo se propuso comprender los sentidos que los exiliados argentinos comprometidos en la denuncia de la última dictadura militar atribuyeron a la figura del Núremberg entre 1976 y 1983.

En este análisis diacrónico fue posible reconocer usos tan tempranos como aquellos que circularon en la coyuntura de descubrimiento de la arena internacional como caja de resonancia de las graves, generalizadas y sistemáticas violaciones a los derechos humanos y en particular acerca de la situación de los detenidos-desaparecidos en el país.

Fue así que en orden a traducir la singularidad represiva argentina en matrices simbólicas universales y de alto impacto ético-político para la consciencia humanitaria global, los exiliados comprendieron que hablar del Núremberg les permitía desnudar la magnitud de la tragedia que vivía su país de origen, desarmar las estrategias de legitimación agitadas por el régimen castrense y tratar de evitar que la comunidad internacional reeditara comportamientos y actitudes que permitieron durante la Segunda Guerra Mundial la consumación del genocidio de los judíos europeos.

Si bien en este escenario temprano y mientras los exiliados luchaban por multiplicar las sanciones económicas, militares y morales al gobierno de Videla, la referencia al Núremberg también comprendió cuestiones doctrinales como la de los "crímenes de guerra" y de "lesa humanidad", no fue sino hasta que la Junta militar comenzó a delinear su estrategia de clausura simbólico-legal del "problema de los desaparecidos" - en una línea ascendente que va desde la promulgación de las "leyes de desaparecidos" hasta la de la "ley de Autoamnistía" - que los exiliados empezaron a asociar Núremberg a hacer justicia. Entendiendo por justicia no sólo hacer memoria - manteniendo en eterno presente los crímenes cometidos, agobiando la consciencia culpable de los perpetradores y mostrando a los familiares de las víctimas su compromiso con la verdad de lo ocurrido -, sino avanzar hacia un "ajuste de cuentas" que lograra sentar en el banquillo de los acusados a los militares argentinos como había ocurrido con los jerarcas nazis en el tribunal de la ciudad alemana.

De este modo, y sin que podamos trazar un derrotero lineal e irreversible en los usos del Núremberg desde un estadio en el que exclusivamente fue motivo de pedagogía e internacionalización hasta otro en el que formó parte de la estrategia jurídico-penal exiliar; lo cierto es que desde que los militares avanzaron en el "borrón y cuenta nueva", la declaración de muerte de los "desaparecidos" y la autoexculpación de sus responsabilidades penales en la "guerra contra la subversión", los desterrados lo agitaron para mostrar que su acción colectiva en la arena internacional no sólo implicaba informar sobre las graves violaciones a derechos y libertades perpetradas por los militares desde que ocuparon el poder del Estado, identificando a los culpables y manteniendo la memoria de las víctimas, sino también luchar por el "juicio y castigo" como piedra angular de la futura democracia. 
Jensen. Los exiliados argentinos y los sentidos del Núremberg: de recurso pedagógico a estrategia de persecución...

\section{Referencias bibliográficas}

Amorós, M. (coord.) (2011). Argentina en el Archivo de IEPALA (1976-1983). Madrid: IEPALA.

Ayala, M. (2014). "Los exiliados argentinos en Venezuela. Solidaridad, denuncia y construcción de redes regionales de Derechos Humanos (1976-1981)". En: S. Jensen y S. Lastra (edits.), Exilios: militancia y represión. Nuevas fuentes y nuevos abordajes de los destierros de la Argentina de los años setenta. La Plata: UDULP, (pp. 121-155). Recuperado de: http://www.memoria.fahce.unlp.edu.ar/ libros/pm.371/pm.371.pdf

Ayala, M. (2018). "Las campañas internacionales de la CLAT contra la última dictadura militar argentina (1976-1982)". En: S. Lastra (Comp.), Exilios: un campo de estudios en expansión (pp. 114-134). Buenos Aires: CLACSO.

Bernetti, J. y Giardinelli, M. (2014). México, el exilio que hemos vivido: memoria del exilio argentino durante la dictadura 1976-1983. Buenos Aires: Editorial Octubre.

CADHU (1979). Testimonios de los sobrevivientes del genocidio en la Argentina Madrid: CADHU.

Catoggio, S. (2018). "Recorrer y tejer las redes del exilio: el caso de una Madre de Plaza de Mayo". En: S. Lastra (Comp.), Exilios: un campo de estudios en expansión (pp. 96-111). Buenos Aires: CLACSO.

Confino, H. (2018). La contraofensiva estratégica de Montoneros (1978-1980). Entre la militancia revolucionaria y el exilio (Tesis doctoral). Buenos Aires: IDAES-UNSAM.

Cristiá, M. (2017). "Imaginación y resistencia antidictatorial en los años ochenta. La acción por América Latina de la Asociación Internacional de Defensa de Artistas Víctimas de la Represión en el Mundo (AIDA"). Revista Izquierdas (36), noviembre, 156180. Recuperado de: $\mathrm{http} / /$ izquierdas.cl/images $/ \mathrm{html} / \mathrm{h} 36 / \mathrm{index} 36 . \mathrm{html}$

Franco, M. (2018). El final del silencio: dictadura, sociedad y derechos humanos en la transición: Argentina, 1979-1983. Buenos Aires: FCE.

FundaLatin (1982) Los desaparecidos. Propuestas para un proyecto de Convención Internacional contra las desapariciones forzadas. Caracas: FundaLatin.

Gabetta, C. (1983). Todos somos subversivos. Buenos Aires: Bruguera.

Gordillo, M. (2017). "Activismo sindical transnacional en el Cono Sur: algunas experiencias". Clepsidra. Revista Interdisciplinaria de Estudios sobre Memoria, vol. 4 (7), 68-83. Recuperado de: http://www.google.com.ar/url?sa=t\&rct=$\mathrm{j} \& \mathrm{q}=\&$ esrc $=\mathrm{s} \&$ source $=$ web $\& \mathrm{~cd}=2 \& v e d=2$ ahUKEwjt7YywqJ3dAhXDTZAKHdJVAFQQFjABegQICRAC\&url=http\%3A\%2F\%2Fppct.caicyt.gov.ar\%2Findex.php $\% 2$ Fclepsidra\%2Farticle $\% 2$ Fdownload\%2FGordillo\%2Fpdf\&us$\mathrm{g}=\mathrm{AOvVaw} 2 \mathrm{~F}-\mathrm{R} 2 \mathrm{w} 91 \mathrm{JP} 35 \mathrm{M} 70$ AyOQiW0

Jensen, S. (coord.) (2016). "Dossier Exilios latinoamericanos y derechos humanos: perspectivas transnacionales". Migraciones y Exilios, 16, 5-106.

Jensen, S. (2018). "La historiografía del último exilio político argentino. Itinerarios y desafíos". En: G. Águila, L. Luciani, L. Seminara y C. Viano (coords.) La Historia Reciente en Argentina. Balances de una historiografia pionera en América Latina. (pp. 93-108). Buenos Aires: Imago Mundi. 
Junta Militar (1980). Observaciones y comentarios críticos del gobierno argentino al informe de la CIDH sobre la situación de los Derechos Humanos en Argentina. Bs As: Círculo Militar.

Timerman, J. (1981). Preso sin nombre, celda sin número. New York: Random Editores.

\section{Publicaciones periódicas del exilio referidas}

Comunidad, Estocolmo (1979-1982).

Controversia. Para el examen de la realidad argentina, México (1979-1981).

Cuadernos de marcha. Segunda época, México (1979-1984).

Presencia Argentina, Madrid (1979-1981).

Resumen de Actualidad Argentina, Madrid (1979-1983).

Testimonio Latinoamericano, Barcelona (1980-1983). 